V. 13 N. 1

JAN-ABR 2017

ISSN 2317-6172

Recebido: 24.09 .2015

Aprovado: 02.02.2017

Dol: http://dx.doi.org/10.1590/2317-6172201709

1 Instituto Federal do Paraná Pato Branco - PR - Brasil

2 Universidade Federal do Paraná Curitiba - PR - Brasil

\section{Suprema Corte e segregação racial nos moinhos da Guerra Fria}

SUPREME COURT AND RACIAL SEGREGATION IN THE COLD WAR MILLS

\author{
Sandro Luís Tomás Ballande Romanelli ${ }^{1}$ \\ e Fabrício Ricardo de Limas Tomio ${ }^{2}$
}

\section{Resumo}

Este artigo investiga a influência da política externa norte-americana na Suprema Corte dos Estados Unidos da América no julgamento do caso Brown v. Board of Education of Topeka, de 1954, buscando demonstrar a permeabilidade daquela Corte aos interesses da política externa norte-americana. Tomando como ponto de partida os argumentos em dois precedentes da Corte envolvendo questões de raça (casos Dred Scott v. Sandford, 1856 e Plessy v. Ferguson, 1896), defende-se que a mudança de entendimento da Corte - que resultou na declaração de inconstitucionalidade das leis de segregação racial nas escolas - tem como um de seus pilares a necessidade de melhoria da imagem dos Estados Unidos no plano internacional, inserida no contexto de Guerra Fria. Neste aspecto, o artigo busca contrapor a tradicional leitura de que o caso seria mostra exemplar do ativismo político da Corte, lançando a hipótese de que a atuação contramajoritária da Suprema Corte foi fortemente incentivada por setores do próprio governo, como demonstram peças processuais e notícias jornalísticas dos bastidores da decisão.

\section{Palavras-chave}

Controle de Constitucionalidade; Suprema Corte norte-americana; segregação racial; Guerra Fria; ativismo judicial.

\begin{abstract}
This paper aims to describe American foreign-policy influences in the United States Supreme Court's ruling Brown v. Board of Education of Topeka (1954), showing evidence that the Court took U. S. Government's foreign-policy into account, although without textually mentioning it. Taking detailed analysis of two race related previous cases (Dred Scott v. Sandford, 1856 and Plessy v. Ferguson, 1896), we believe we are able to demonstrate that the 1954 Supreme Court's motivation to overrule its binding precedents and to declare school segregation unconstitutional was directly influenced by United States foreign-policy interests to improve the country's international image towards racial inclusion, opposing Soviet Union's widely spread anti-American propaganda during the Cold War. In that context, relying on cases Briefs and Newspapers headlines from the 50's, we claim that Brown case should not be reviewed only as a classic example of Supreme Court's activism in counter-majoritarian context, but otherwise, the case could be understood as an example of government driven interests that pushed the Court to that decision.
\end{abstract}

\section{Keywords}

Judicial Review; U. S. Supreme Court; racial segregation; Cold War; judicial activism. 


\section{INTRODUÇÃO}

A discriminação racial leva água ao moinho da propaganda comunista e levanta dúvidas, mesmo entre nações amigas, sobre a intensidade de nossa devoção à fé democrática (McGRANERY, 1952, p. 3, tradução nossa). ${ }^{1}$

A frase em epígrafe foi escrita por James P. McGranery, procurador-geral dos Estados Unidos da América (EUA) ${ }^{2}$ em petição protocolada em dezembro de 1952 como amicus curiae nos autos do processo Brown v. Board of Education of Topeka, decidido em 1954 (KLINKNER; SMITH, 1999, p. 235). O caso foi considerado um dos grandes marcos de afirmação dos direitos civis e da igualdade racial naquele país, recebendo grande cobertura da mídia (LESTER, 2004) e repercutindo na doutrina de Direito Constitucional dos 50 anos seguintes (BELL, 1995; THOMAS, 2002; SUNSTEIN, 2004).

Um dos aspectos interessantes do caso Brown reside na constatação de que houve uma feliz convergência de interesses da política externa com as pressões nos direitos civis, levando à existência de incentivos que franquearam à Suprema Corte maior liberdade para declarar a inconstitucionalidade da segregação racial em escolas públicas. É o que se pretende demonstrar no presente artigo.

Muita água correu nas questões raciais em face da Suprema Corte. Antes de analisar a decisão de Brown v. Board of Education of Topeka, de 1954, vamos destacar alguns elementos importantes de dois casos precedentes: Dred Scott v. Sandford, de 1856 e Plessy v. Ferguson, de 1896. Veremos que o caminho para o caso Brown não contou com águas tranquilas.

\section{A SOCIEDADE SEgRegadA:}

QUestões Raciais diante da Suprema Corte no século XIX

\section{I A liberdade Para Dred Scott, i 856: A NEGAÇ̃̃o DA CIDADANia}

No caso Dred Scott v. Sandford (U. S. SUPREME COURT, 1856), um ex-escravo e sua mulher

1 No original: "Racial discrimination furnishes grist for the Communist propaganda mills, and it raises doubts even among friendly nations as to the intensity of our devotion to the democratic faith" (McGRANERY, 1952, p. 3).

2 A petição de McGranery manifestava a política externa do presidente Harry S. Truman. Truman tornou-se presidente após a morte de Franklin D. Roosevelt, em 1945, permanecendo nesse cargo até janeiro de 1953. Em seu governo, os EUA terminaram sua participação na Segunda Guerra Mundial (mediante o controverso uso da bomba atômica no Japão, há exatos 70 anos) e iniciou a guerra contra o comunismo, conhecido como doutrina Truman. Entretanto, a decisão do caso Brown v. Board of Education of Topeka, em 1954, ocorreu sob a presidência de Dwight D. Eisenhower, republicano eleito 
ingressaram em juízo contra o Sr. John F. A. Sanford, ${ }^{3}$ pleiteando o direito de permanecerem livres após terem sido arrolados como bens no inventário de seu falecido proprietário. ${ }^{4}$

Scott arguiu que, como havia sido levado em 1833 a serviço pelo seu antigo proprietário para o Estado de Illinois - um dos "Estados-livres" como eram conhecidos aqueles nos quais a escravidão era proibida - e depois tendo ainda residido em uma área do território de Louisiana - então território federal, no qual a escravidão também era proibida pela lei conhecida como Missouri Compromise de 1820 -, teria adquirido o status de liberto. Assim, ao voltar em 1843 ao Missouri (Estado escravocrata), teria retornado na condição de cidadão livre, não podendo ser reduzido novamente a escravo.

No julgamento da Suprema Corte, presidida pelo Chief Justice Roger B. Taney, a questão foi decidida com base em questões processuais. ${ }^{\mathbf{5}}$ Taney, cujo voto se tornou a opinion of the Court, primeiramente investigou a definição de cidadão e de “povo dos Estados Unidos” no contexto da elaboração da Constituição, em 1787, afirmando tratar-se do corpo político que forma a soberania e que detém o poder, conduzindo o governo por meio de seus representantes:

As palavras 'povo dos Estados Unidos' e 'cidadãos' são termos sinônimos e significam a mesma coisa. Ambas descrevem o corpo político que, de acordo com nossas instituições republicanas, forma a soberania e detêm o poder, conduzindo o governo por meio de seus representantes. Eles são o que nós chamamos familiarmente de 'povo soberano', e cada cidadão é parte integrante desse povo e membro constituinte da soberania (U. S. SUPREME COURT, 1856, p. 15, tradução nossa, grifo nosso). ${ }^{6}$

em 1952. Foi Einsenhower quem indicou Earl Warrren como Chief Justice para a Suprema Corte, em outubro de 1953. Warren viria a ser um ator fundamental para a decisão do caso Brown.

3 O nome do demandado (John Sanford) foi incorretamente grafado, constando no registro oficial do caso Sandford em vez de Sanford.

4 O requerido, John Sanford, era irmão de Eliza Emerson e inventariante dos seus bens, dentre os quais estavam arrolados Dred Scott e sua esposa. Após sofrer derrotas nas ações movidas contra a Senhora Emerson na justiça do Estado do Missouri (Scott v. Emerson, 1852), os advogados de Dred Scott adotaram a estratégia de mover nova ação contra Sanford, eis que ele residia no Estado de Nova Iorque, permitindo que o caso fosse ajuizado nas cortes federais por envolver litigantes com domicílio em diferentes Estados da federação (GRABER, 2006, p. 18).

5 Conforme indica Mark Graber (p. 19), a decisão é longa e não muito clara: "The precise holding of Dred Scott is not entirely clear. All nine justices wrote opinions, and the seven justices in the majority gave different reasons for rejecting Scott's appeal”.

6 No original: "The words 'people of the United States' and 'citizens' are synonymous terms, and mean the same thing. They both describe the political body who, according to our republican institutions, form the 
Em seguida, o voto desenvolveu a ideia de que Dred Scott, como descendente de africanos trazidos aos Estados Unidos como escravos, não poderia ser considerado cidadão americano para os termos da Constituição, pois tal grupo de pessoas não fazia parte do "povo soberano" que constituía o grupo político que o texto constitucional pretendia proteger:

A questão à nossa frente reside em saber se a classe de pessoas descrita na petição sob análise compõe a porção deste povo e são membros constituintes dessa soberania. Acreditamos que a resposta é negativa, que eles não são incluídos e não houve intenção de incluí-los sob a palavra 'cidadãos' na Constituição. Desta forma, não podem pleitear nenhum dos direitos e privilégios que este instrumento normativo prevê e assegura aos cidadãos dos Estados Unidos (U. S. SUPREME COURT, 1856, p. 15, tradução nossa, grifo nosso). ${ }^{7}$

Para sustentar sua afirmação, Taney ressalta o passado de dominação racial e subordinação de grupos como classe inferior de sujeitos, arguindo que não caberia à Suprema Corte a decisão sobre a justiça ou conveniência política de tais leis. Afirma, expressamente, que a decisão para tal questão caberia ao poder político ou Legislativo, sendo papel da Corte apenas interpretar o instrumento constitucional de acordo com a verdadeira intenção e sentido desejado pelos seus redatores quando de sua adoção:

Ao contrário, naquele tempo eles eram considerados como uma classe subalterna e inferior de pessoas, que foram subjugadas pela raça dominante e, emancipados ou não, ainda permaneceram sujeitos à sua autoridade, desprovidos de direitos ou privilégios além daqueles que os detentores do poder e o governo escolheram conceder-lhes.

Não é da competência desta corte decidir sobre a justiça ou injustiça, a correção ou incorreção política destas leis. A decisão para esta questão pertence ao poder político ou legiferante; para aqueles que formaram a soberania e moldaram a Constituição. A missão da Corte é de interpretar o instrumento que

sovereignty, and who hold the power and conduct the Government through their representatives. They are what we familiarly call the 'sovereign people', and every citizen is one of this people, and a constituent member of this sovereignty" (U. S. SUPREME COURT, 1856, p. 15, grifo nosso).

$7 \quad$ No original: "The question before us is, whether the class of persons described in the plea in abatement compose a portion of this people, and are constituent members of this sovereignty? We think they are not, and that they are not included, and were not intended to be included, under the word 'citizens' in the Constitution, and can therefore claim none of the rights and privileges which that instrument provides for and secures to citizens of the United States" (U. S. SUPREME COURT, 1856, p. 15, grifo nosso). 


\section{moldaram sob o melhor enfoque que se pode obter sobre o assunto e, desta forma, administrar o que for resultante, de acordo com a verdadeira intenção e sentidos de quando o documento foi adotado (U. S. SUPREME COURT, 1856 , p. 15, tradução nossa, grifos nossos). ${ }^{8}$}

Não bastasse a utilização, como argumento de justificação para a decisão, da "vontade do constituinte de 1787”, legislador de praticamente 70 anos antes (o que, por si só, dificultaria o reconhecimento da legitimidade da decisão nos estados mais modernos), o julgamento deixou o contexto político ainda mais conturbado ${ }^{9}$ ao declarar a inconstitucionalidade da legislação que proibia a escravidão do território federal da Louisiana, conhecida como o Missouri Compromise, de 1820. A Suprema Corte afirmava, assim, que o legislador federal não poderia conferir liberdade a pessoas tidas como escravas pela legislação estadual:

$\mathrm{O}$ ato do Congresso sobre o qual o reclamante sustenta seu inconformismo declara que a escravidão e servidão involuntária, com exceção de sua forma como punição para o crime, devem ser proibidas para sempre em todo o território cedido pela França sob o nome de Louisiana, que se situa ao norte de trinta e seis graus e trinta minutos de latitude norte, e não incluídas nos limites do Missouri. E a dificuldade com que nos deparamos no limiar desta parte da indagação é saber se o Congresso foi autorizado a aprovar esta lei nos termos de quaisquer dos poderes que lhe foram conferidos pela Constituição; pois, se a autoridade não é dada por esse instrumento, é dever deste tribunal declará-lo nulo e inoperante, portanto incapaz de conferir a liberdade a qualquer um que é tido como um escravo sob a legislação de qualquer um dos Estados (U. S. SUPREME COURT, 1856, p. 29, tradução nossa, grifo nosso). ${ }^{10}$

8 No original: "On the contrary, they were at that time considered as a subordinate and inferior class of beings, who had been subjugated by the dominant race, and, whether emancipated or not, yet remained subject to their authority, and had no rights or privileges but such as those who held the power and the Government might choose to grant them. It is not the province of the court to decide upon the justice or injustice, the policy or impolicy, of these laws. The decision of that question belonged to the political or law-making power; to those who formed the sovereignty and framed the Constitution. The duty of the court is, to interpret the instrument they have framed, with the best lights we can obtain on the subject, and to administer it as we find it, according to its true intent and meaning when it was adopted" (U. S. SUPREME COURT, 1856, p. 15, grifos nossos).

9 A decisão da Suprema Corte norte-americana no caso Dred Scott foi tida como um dos impasses institucionais que levou ao início, em 1860, da Guerra de Secessão americana, conhecida na história norte-americana como Civil War.

10 No original: "The act of Congress, upon which the plaintiff relies, declares that slavery and involuntary servitude, except as a punishment for crime, shall be forever prohibited in all that part of the territory ceded by France, under 
De acordo com o voto, na condição de descendente de escravos africanos, ainda que nascido em solo norte-americano, Dred Scott não tinha o direito constitucional à cidadania e não poderia, portanto, ser demandante - no standing rights - naquela Corte. Desta forma, por sete votos a dois, a Corte afirmou que Scott não tinha legitimidade para ingressar em juízo na Corte federal, faltando-lhe para tanto a condição de cidadão.

Uma importante nota para aprofundar a análise do julgamento no caso Dred Scott é feita por Mark Graber (2006), que indica que a decisão da Suprema Corte foi tomada com apoio político majoritário:

A decisão da Corte Taney sobre a cidadania capturou o "igualitarismo Herrenvolk" [na qual apenas um grupo étnico preponderante participa do governo], concepção política dominante do meio do século XIX. A escravidão era local, mas o racismo era nacional. Jacksonianos em ambos os estados livres e escravocratas concordavam no sentido de que a igualdade deveria ser aplicável apenas entre homens brancos. Pessoas de cor eram consideradas como biologicamente inferiores, talvez até mesmo como membros de uma espécie diferente. [...] A decisão da Corte Taney para determinar o estatuto constitucional da escravidão nos territórios recebeu apoio majoritário em 1857, assim como o sentido substantivo da decisão também recebeu amplo apoio (GRABER, 2006, p. 31-33, tradução nossa, grifos nossos). ${ }^{11}$

Sem deixar dúvidas quanto ao apoio político recebido pela Suprema Corte para a decisão do caso, Graber afirma ainda que "Dred Scott foi 'realizado somente sob o convite explícito do Congresso' e do presidente” (GRABER, 2006, p. 33).

Da mesma forma, Jack Balkin e Sanford Levinson afirmam que, além de questões econômicas em torno da escravidão, também estava no centro da doutrina constitucional o perigo

the name of Louisiana, which lies north of thirty-six degrees thirty minutes north latitude, and not included within the limits of Missouri. And the difficulty which meets us at the threshold of this part of the inquiry is, whether Congress was authorized to pass this law under any of the powers granted to it by the Constitution; for if the authority is not given by that instrument, it is the duty of this court to declare it void and inoperative, and incapable of conferring freedom upon any one who is held as a slave under the have of any one of the States" (U. S. SUPREME COURT, 1856, p. 29, grifo nosso).

11 No original: "The Taney Court ruling on citizenship captured the dominant "herrenvolk egalitarianism" of the middle nineteenth century. Slavery was local, but racism was national. Equality, Jacksonians in both the free and slave states agreed, was equality for white males. Persons of color were regarded as biologically inferior, perhaps even a different species. [...] The Taney Court's decision to determine the constitutional status of slavery in the territories enjoyed the same majoritarian support in 1857 as did the substance of the decision the justices made" (GRABER, 2006, p. 31-33, grifos nossos). 
de que uma decisão pudesse causar a dissolução da União. Nesse sentido, a reação dos Estados escravocratas a uma decisão favorável a Dred Scott era uma preocupação relevante para os ministros da Suprema Corte (BALKIN; LEVINSON, 2007, p. 66).

Nesse período político conturbado, a Suprema Corte recebeu apoio político para estabelecer uma agenda partidária de julgamentos e também apoio no resultado de suas decisões, obtendo assim legitimidade para atuar de forma incisiva em grandes debates da metade do século XIX:

Jacksonianos [precursores do partido Democrata] dos Estados-livres [abolicionistas] desejavam que o Tribunal decidisse o caso Dred Scott, endossando a decisão judicial resultante e pedindo por novas decisões judiciais sobre as questões mais controvertidas da ordem do dia. [...] Os Jacksonianos fizeram grandes esforços para promover políticas públicas por meio de decisões judiciais - e dar suporte às decisões tomadas pela justiça -, o que demonstra que o Ministro Taney não impôs sua decisão sobre um Congresso hostil ou sobre uma Nação avessa à solução judicial da questão da cidadania dos negros ou da escravidão nos territórios. A decisão [do caso] Dred Scott era tão majoritária como qualquer outra política pública sobre raça ou a escravidão elaborada durante a década de 1850. (GRABER, 2006 , p. 35, tradução nossa, grifos nossos). ${ }^{12}$

Finalmente, o caso Dred Scott, cuja decisão foi duramente criticada pela doutrina como sendo uma das mais equivocadas da Suprema Corte (GRABER, 2006; KLINKNER; SMITH, 1999; MILNER IV; LOMOTEY, 2014), pois ainda que não tenha sido unânime, ${ }^{13}$ foi decisivo

No original: "Free-state Jacksonians wanted the Court to decide Dred Scott, endorsed the resulting judicial decision, and continued calling for judicial decisions on the most controversial issues of the day. [...] These frequent Jacksonian efforts to foster judicial policy making-combined with strong Jacksonian support for the policies the justice made - demonstrate that Taney did not impose a judicial solution to the question of black citizenship or slavery in the territories on a hostile Congress or nation. The Dred Scott decision was as majoritarian as any other race or slavery policy made during the 1850s" (GRABER, 2006, p. 35, grifos nossos).

Dred Scott v. Sandford não foi um julgamento unânime. É digno de nota que os ministros John McLean e Benjamin Curtis registraram sua discordância lavrando dissenting opinions. Curtis defendeu que a Suprema Corte não teria competência para julgar. Buscava evitar que uma decisão em qualquer sentido pudesse contribuir para amplificar os já inflamados discursos políticos e a tensão entre os Estados escravocratas e os Estados livres. Ainda assim, Curtis apontava como forte argumento a favor de Dred Scott o fato de que os proprietários haviam consentido para que contraísse matrimônio, condição que pressupunha plena capacidade jurídica e que, portanto, teria como consequência lógica a emancipação de Scott e de sua esposa (MALTZ, 2007, p. 269). O voto do ministro McLean indicava que a interpretação originalista sobre a intenção dos formuladores da constituição estava equivocada, eis que ao tempo da assinatura da carta 
para acirrar o embate político que levou à guerra civil de 1961-1965. O precedente foi superado com a promulgação da décima quarta emenda à Constituição em 1868, após o fim da Guerra de Secessão no contexto das chamadas "Emendas de Reconstrução" (Reconstruction Amendments $-13^{\mathrm{a}}, 14^{\mathrm{a}}$ e $15^{\mathrm{a}}$ Emendas Constitucionais). ${ }^{14}$

\section{i.2 A igualdade para Homer Plessy, i 896:}

UM HOMEM NEGRO NÃO TEM O DIREITO À REPUTAÇÃO DE SER UM HOMEM BRANCO

Plessy reconfigurou a relação assimétrica entre negros e brancos como igualdade não haveria violação constitucional porque Negros e brancos estavam igualmente sujeitos a uma regra de exclusão (HARRIS, 2004, p. 190, tradução nossa). ${ }^{15}$

Em junho 1892, Homer Plessy comprou um ingresso para o vagão da primeira classe no trem de New Orleans para Covington, no Estado da Louisiana. Ao acomodar-se em um vagão onde só havia passageiros brancos, foi interpelado pelo condutor para que deixasse o vagão e fosse ocupar outro assento, em um vagão destinado a pessoas "não brancas". Diante da recusa de Plessy, a polícia foi chamada e levou-o preso por violação à Lei n. 111, de 1890, do Estado da Louisiana, conhecida como a "Lei dos vagões separados" (Separate Car Act). Tal lei determinava que a companhia de trem de passageiros devesse fornecer iguais, porém distintas acomodações para as raças branca e não branca.

Todas as empresas de transporte ferroviário transportando passageiros em seus vagões, neste estado, devem fornecer acomodações iguais, mas separadas, para as raças brancas e coloridas, fornecendo dois ou mais vagões para cada comboio de passageiros, ou repartindo os vagões de passageiros por meio de uma divisória, de modo a garantir acomodações separadas. Esta seção não se aplica aos transportes urbanos. Nenhuma pessoa ou grupo de pessoas será autorizada a ocupar assentos em vagões

constitucional, cinco dos 13 Estados signatários já haviam concedido o direito de voto aos cidadãos negros, incluindo-os no conceito de cidadãos norte-americanos (BALKIN; LEVINSON, 2006, p. 69).

14 Com o fim da Guerra de Secessão em 1865, foram promulgadas três Emendas Constitucionais (13 ${ }^{\mathrm{a}}, 14^{\mathrm{a}}$ e 15ªmendas) conhecidas como as "Emendas de Reconstrução" (The Reconstruction Amendments). Em linhas gerais, estabeleciam o fim da escravidão em solo norte-americano $\left(13^{\mathrm{a}}\right)$; o direito de cidadania para toda pessoa nascida em território norte-americano $\left(14^{\mathrm{a}}\right)$ e o direito ao voto de todo cidadão, sendo vedada a discriminação por raça, cor ou prévia condição de servidão (1 $5^{a}$ Emenda).

No original: "Plessy reconfigured the asymmetrical relationship between Blacks and whites as equality - there was no constitutional violation because Blacks and whites were equally subject to a rule of exclusion"(HARRIS, 2004, p. 190). 
diversos daqueles que lhe forem atribuídos, por conta da raça a que pertence (Louisiana Act n. 111, p. 152, 1890, tradução nossa, grifo nosso). ${ }^{16}$

A viagem frustrada de Plessy havia sido cuidadosamente planejada. Desde a aprovação da Separate Car Act, em 1890, um grupo de proeminentes negros, mestiços e brancos de $\mathrm{NeW}$ Orleans formou um comitê de cidadãos (Comité des Citoyens) para combater a legislação segregacionista (COVER, 1982; HARRIS, 2004, p. 208). O grupo conseguiu convencer Homer Plessy a ajudá-los a desafiar a lei, de forma que pudessem ingressar em juízo e combater a constitucionalidade da legislação. Plessy foi escolhido justamente por ser um mestiço extremamente claro, com 7/8 de ascendência branca e apenas um bisavô negro. Os advogados do caso tinham a esperança de, assim, chamar ainda mais a atenção da Corte para as incongruências da lei (HARRIS, 2004, p. 210; KLINKNER; SMITH, 1999, p. 222).

Após ser condenado a pagar uma multa pelo magistrado John Howard Ferguson, Plessy manejou um remédio processual na Suprema Corte do Estado da Louisiana e, mantida a decisão, novo recurso fazendo o caso chegar à Suprema Corte norte-americana (COVER, 1982). Desde o julgamento do caso Dred Scott na Suprema Corte, haviam se passado uma guerra, três emendas constitucionais e praticamente 40 anos. Em maio de 1896, o caso foi decidido, mas ainda não seria nesta ocasião que a Suprema Corte formaria seu prestígio na defesa das minorias.

\section{I .2 . i Os argumentos Jurídicos: "Se ele for um Homem Branco..."}

Os advogados de Plessy arguiram que a Separate Car Act da Louisiana era inconstitucional à luz das emendas 13 e 14 da Constituição. Como violação à $13^{\text {a }}$ Emenda - que estabelecia o fim da escravidão e da servidão involuntária -, alegaram que a separação das duas raças nos vagões "estampava" nos negros uma "marca de inferioridade”, condição que a alteração constitucional visava extinguir. Quanto à violação da $14^{\mathrm{a}}$ Emenda (garantindo cidadania plena a todos os nascidos no território norte-americano e, portanto, igual proteção da lei), o argumento jurídico foi ainda mais sofisticado (HARRIS, 2004, p. 217). Ao retirar Plessy do vagão destinado aos brancos por considerá-lo negro, o funcionário da companhia teria violado a reputação ${ }^{17}$ de Plessy de pertencer à raça dominante.

16 No original: "[A]11 railway companies carrying passengers in their coaches in this state, shall provide equal but separate accommodations for the white, and colored races, by providing two or more passenger coaches for each passenger train, or by dividing the passenger coaches by a partition so as to secure separate accommodations: provided, that this section shall not be construed to apply to street railroads. No person or persons shall be permitted to occupy seats in coaches, other than the ones assigned to them, on account of the race they belong to" (Louisiana Act n. 111, p. 152, 1890, grifo nosso).

17 É importante lembrar que Homer Plessy era praticamente branco. Havia sido escolhido exatamente por conta de sua origem mestiça, com apenas um bisavô negro e outros sete brancos. 
Tal reputação - de "ser branco" - representaria direito equivalente à propriedade, com palpáveis efeitos econômicos:

[...] porque a reputação de ser considerado branco era de inegável valor, $o$ poder de um funcionário de trem para determinar arbitrariamente que um passageiro não seria de fato branco - ainda que pudesse desfrutar da reputação de ser considerado como um homem branco -, violava garantias constitucionais contra expropriação sem o devido processo legal. A propriedade da brancura era de enorme significado e de valor auto-evidente (HARRIS, 2004, p. 216-217, tradução nossa, grifos nossos). ${ }^{18}$

O argumento retórico para demonstrar o valor de ser branco foi levado ao extremo por Albion Tourgée, um dos advogados de Homer Plessy. Ao demonstrar que a maior parte das oportunidades profissionais e comerciais na sociedade norte-americana favorecia pessoas brancas, afirma que estes prefeririam, em sua maioria, morrer a viver nos Estados Unidos como uma pessoa de cor! Tal "status social", de ser reconhecido como branco seria, portanto, como a mais valiosa das propriedades, verdadeira chave mestra que abriria "a porta dourada da oportunidade":

Quanto valeria para um jovem iniciante na advocacia ser considerado como um homem branco ao invés de uma pessoa de cor? Seis sétimos da população são homens brancos. Dezenove-vigésimos centésimos de oportunidades de negócios estão no controle de pessoas brancas [...]. Provavelmente, se pudessem escolher, pessoas brancas prefeririam a morte à vida nos Estados Unidos como pessoas de cor. Nestas condições, seria factível concluir que a reputação de ser branco não constitui propriedade? Na verdade, não seria a mais valiosa espécie de propriedade, a chave-mestra que abre a porta dourada da oportunidade? (TOURGÉE apud HARRIS, 2004, p. 217, tradução nossa, grifos nossos). ${ }^{19}$

No original: "[...] because the reputation in being regarded as white was of undeniable value, empowering a train employee to determine arbitrarily that a passenger who might enjoy the reputation of being regarded as a white man was not in fact white violated constitutional guarantees against the taking of property without due process of law. This property in whiteness was of overwhelming significance and self-evident value" (HARRIS, 2004, p. 216-217, grifos nossos).

19 No original: "How much would it be worth to a young man entering upon the practice of law, to be regarded as a white man rather than a colored one? Six-sevenths of the population are white. Nineteen-twentieths hundredths of the business opportunities are in the control of white people... Probably most white persons if given a choice, would prefer death to life in the United States as colored persons. Under these conditions, is it possible to conclude that the reputation of being white is no property? Indeed, is it not the most valuable 
A Suprema Corte foi insensível a estes argumentos. Por sete votos a um, julgou pela improcedência da demanda (com Justice Brown redigindo a opinião da Corte), decidindo que a lei dos vagões separados da Louisiana era constitucional, pois tratava igualmente, de forma isonômica, negros e brancos.

Em resposta aos argumentos de que Homer Plessy teria sido injustamente destituído de sua propriedade (a "reputação" de ser branco), Justice Brown afirma que Plessy não tinha tal direito, eis que simplesmente não era branco! Somente caso o fosse, poderia então pleitear uma indenização:

Se ele for um homem branco designado para um vagão de pessoas de cor, ele pode obter sucesso em sua ação de indenização contra a empresa por ter sido privado de alegada "propriedade". Por outro lado, se ele for um homem de cor designado para o vagão devido, não terá sido privado de nenhuma propriedade, uma vez que ele não está legalmente legitimado a desfrutar da reputação de ser um homem branco (U. S. SUPREME COURT, 1896, p. 6, tradução nossa, grifos nossos). ${ }^{20}$

Quanto à inconstitucionalidade da lei com fundamento na $13^{\mathrm{a}}$ Emenda, de abolição da escravidão e servidão por dívidas, Justice Brown considerou que a alegada inferioridade era uma sensação subjetiva, verdadeira falácia argumentativa, sendo que a mera distinção de vagões por cores não tinha o condão de estabelecer uma hierarquia entre raças:

\section{Consideramos que a falácia subjacente ao argumento do demandante consiste na suposição de que a separação forçada das duas raças marca a raça negra com um emblema de inferioridade. Se isto é assim, não é por causa de qualquer coisa encontrada no ato, mas apenas porque a raça de cor escolhe colocar essa construção sobre si (U. S. SUPREME COURT, 1896, p. 7, tradução nossa, grifo nosso). ${ }^{21}$}

sort of property, being the master-key that unlocks the golden door of opportunity?" (TOURGÉE apud HARRIS, 2004, p. 217, grifos nossos).

No original: "If he be a white man, and assigned to a colored coach, he may have his action for damages against the company for being deprived of his so called 'property.' Upon the other hand, if he be a colored man, and be so assigned, he has been deprived of no property, since he is not lawfully entitled to the reputation of being a white man” (U. S. SUPREME COURT, 1896, p. 6, grifos nossos).

No original: "We consider the underlying fallacy of the plaintiff's argument to consist in the assumption that the enforced separation of the two races stamps the colored race with a badge of inferiority. If this be so, it is not by reason of anything found in the act, but solely because the colored race chooses to put that construction upon it" (U. S. SUPREME COURT, 1896, p. 7, grifo nosso). 
Ainda no mesmo matiz, o argumento segue para demonstrar que, existindo diferenças baseadas na diferença de cor entre brancos e negros e sendo estas um traço distintivo concreto entre elas, a mera distinção entre as raças não teria o condão de destruir a igualdade jurídica ou reestabelecer um estado de servidão involuntária:

Um estatuto que implica apenas na distinção legal entre as raças brancas e de cor - uma distinção que se baseia na cor das duas raças, e que deverá sempre existir enquanto os homens brancos forem distinguidos de outra raça por sua cor - não tem tendência para destruir a igualdade jurídica das duas raças, ou restabelecer um estado de servidão involuntária. Na verdade, nós não entendemos que a $13^{a}$ emenda, vigorosamente invocada pelo recorrente, guarde conexão com este argumento (U. S. SUPREME COURT, 1896, p. 3, tradução nossa, grifo nosso). ${ }^{22}$

Afastando quaisquer dúvidas sobre o modelo de sociedade tomado como ponto de partida para fundamentar sua decisão, Justice Brown afirmou que, embora a $14^{a}$ Emenda visasse estabelecer a absoluta igualdade das raças diante da lei, não poderia abolir as distinções baseadas na cor por conta da "natureza das coisas":

O objeto da emenda foi, sem dúvida, impor a igualdade absoluta das duas raças perante a lei, mas, na natureza das coisas, não poderia ter sido destinada a abolir distinções baseadas na cor; ou para impor a igualdade social como distinta da política; ou uma mistura das duas raças sobre termos insatisfatórios para ambas (U. S. SUPREME COURT, 1896, p. 4, tradução nossa, grifo nosso). ${ }^{23}$

Finalmente, discorrendo sobre a ineficácia da lei para induzir modificações da sociedade, a Corte declarava que a "legislação é desprovida de poder para erradicar instintos raciais, ou para abolir distinções baseadas em diferenças físicas. Se uma raça é socialmente

No original: "A statute which implies merely a legal distinction between the white and colored races - a distinction which is founded in the color of the two races, and which must always exist so long as white men are distinguished from the other race by color - has no tendency to destroy the legal equality of the two races, or re-establish a state of involuntary servitude. Indeed, we do not understand that the thirteenth amendment is strenuously relied upon by the plaintiff in error in this connection" (U. S. SUPREME COURT, 1896, p. 3, grifo nosso).

No original: "The object of the amendment was undoubtedly to enforce the absolute equality of the two races before the law, but, in the nature of things, it could not have been intended to abolish distinctions based upon color, or to enforce social, as distinguished from political, equality, or a commingling of the two races upon terms unsatisfactory to either" (U. S. SUPREME COURT, 1896, p. 4, grifo nosso). 
inferior à outra, a Constituição dos Estados Unidos não pode colocá-las no mesmo plano" (U. S. SUPREME COURT, 1896, p. 7, tradução nossa). ${ }^{24}$

\section{i 2.2 O voto vencido: "Our constitution is COlOR-Blind”}

A despeito do contundente discurso segregacionista do voto proferido por Justice Brown, houve uma voz dissidente na Suprema Corte.

O magistrado John Marshall Harlan denunciou em seu voto vencido a hipocrisia da doutrina do separate but equal, demonstrando que a legislação em análise (a separate cars act) existia para tão somente excluir os negros do convívio dos brancos, e não o oposto:

Cada um sabe que a lei em questão não teve como origem o objetivo de excluir as pessoas brancas de vagões ocupados por negros, mas sim a finalidade de excluir pessoas de cor de vagões ocupados por ou atribuídos a pessoas brancas (U. S. SUPREME COURT, 1896, p. 9, tradução nossa, grifo nosso). ${ }^{25}$

Harlan ironizou a aparente igualdade da segregação em vagões distintos, afirmando que tais "iguais acomodações" garantidas pela legislação do Estado de Louisiana não passavam de um fino disfarce (thin disguise of 'equal' accommodations), inconsistente com a liberdade dos cidadãos e hostil ao espírito e letra da Constituição:

\section{O fino disfarce de acomodações "iguais" para os passageiros dos vagões da estrada de ferro não vai enganar ninguém, nem expiar o mal realizado neste} dia. [...] Eu sou da opinião de que o Estado da Louisiana é incoerente com a liberdade pessoal dos cidadãos, brancos e negros, nesse Estado, e hostil tanto ao espírito quanto à letra da Constituição dos Estados Unidos (U. S. SUPREME COURT, 1896, p. 12, tradução nossa, grifo nosso). ${ }^{26}$

24 No original: "Legislation is powerless to eradicate racial instincts, or to abolish distinctions based upon physical differences, If one race be inferior to the other socially, the constitution of the United States cannot put them upon the same plane” (U. S. SUPREME COURT, 1896, p. 7).

No original: "Every one knows that the statute in question had its origin in the purpose, not so much to exclude white persons from railroad cars occupied by blacks, as to exclude colored people from coaches occupied by or assigned to white persons" (U. S. SUPREME COURT, 1896, p. 9, grifo nosso).

No original: "The thin disguise of 'equal' accommodations for passengers in railroad coaches will not mislead anyone, nor atone for the wrong this day done. [...] I am of opinion that the state of Louisiana is inconsistent with the personal liberty of citizens, white and black, in that state, and hostile to both the spirit and letter of the constitution of the United States" (U. S. SUPREME COURT, 1896, p. 12, grifo nosso). 
Em sua argumentação, Justice Harlan destacava a iniquidade existente entre brancos e negros nos campos econômico e social, reconhecendo que "[a] raça branca se reconhece como a raça dominante deste país. E assim o é em prestígio, em realizações, em educação, em riqueza e em poder" (U. S. SUPREME COURT, 1896, p. 10, tradução nossa). ${ }^{27}$

Entretanto, afirmou Harlan, tal desigualdade na estrutura social não corresponderia à igualdade prevista pela Constituição. Ao desenvolver seu argumento, cunhou a expressão que se tornaria famosa no meio jurídico, afirmando: "Nossa Constituição é cega quanto à cor e nem distingue ou tampouco tolera classes entre os cidadãos" (U. S. SUPREME COURT, 1896, p. 10, tradução nossa).

Eis adiante a transcrição do trecho:

Mas, em vista da constituição, aos olhos da lei, não existe neste país classe superior de cidadãos dominantes ou dirigentes. Não há castas aqui. Nossa constituição é cega quanto à cor e nem distingue ou tampouco tolera classes entre os cidadãos. No que diz respeito aos direitos civis, todos os cidadãos são iguais perante a lei. O mais humilde é parceiro do mais poderoso. A lei considera o homem como homem, e não leva em conta o seu entorno ou a sua cor quando se trata dos seus direitos civis na forma como garantidos pela lei suprema do país (U. S. SUPREME COURT, 1896, p. 10, tradução nossa, grifo nosso). ${ }^{28}$

Em seu artigo sobre o caso Plessy (The story of Plessy v. Ferguson), Cheryl Harris destaca a importância do voto vencido proferido por Justice Harlan. Para Harris (2004, p. 188), a maior virtude de Harlan estaria justamente em denunciar que o suporte jurídico à segregação racial não passaria de um fino disfarce para legitimar e manter a supremacia dos brancos. Sua opinião é vanguardista por condenar a segregação racial fomentada pelo Estado, em um tempo em que a subordinação dos negros era vista como parte da ordem natural das coisas:

No entanto, ao contrário de Dred Scott, Plessy parece ter uma virtude redentora: a solitária dissidência do ministro Harlan denunciou a aprovação, pela maioria da Corte, da segregação de jure como um "fino disfarce", por meio do qual a sujeição dos negros

No original: "The white race deems itself to be the dominant race in this country. And so it is in prestige, in achievements, in education, in wealth and in power" (U. S. SUPREME COURT, 1896, p. 10, grifo nosso).

28 No original: "But in view of the constitution, in the eye of the law, there is in this country no superior, dominant, ruling class of citizens. There is no caste here. Our constitution is color-blind, and neither knows nor tolerates classes among citizens. In respect of civil rights, all citizens are equal before the law. The humblest is the peer of the most powerful. The law regards man as man, and takes no account of his surroundings or of his color when his civil rights as guaranteed by the supreme law of the land are involved" (U. S. SUPREME COURT, 1896, p. 10, grifo nosso). 
era legitimada e mantida. De certa forma, a genialidade da dissidência de Harlan reside em sua premonição: mesmo num momento em que a subordinação dos negros era vista como parte da ordem natural, Harlan condenou a segregação forçada pelo Estado como um sistema de casta racial que era incompatível com a figura de uma cidadania nacional, outorgada constitucionalmente pelas emendas de reconstrução (HARRIS, 2004, p. 188, tradução nossa). ${ }^{29}$

A despeito do brilhantismo da dissidência manifestada por Justice Harlan, sua opinião passou a ser citada em decisões do final do século XX para fundamentar um novo tipo de formalismo, o que visa banir das políticas públicas toda e qualquer consideração sobre raça, mesmo que façam parte de ações afirmativas e planos para remediar efeitos raciais (HARRIS, 2004, p. 189).

Cheryl Harris conclui que, apesar do repúdio praticamente universal sobre a decisão da Suprema Corte no caso Plessy, o voto vencido proferido por Justice Harlan tornou-se a fonte para uma das mais conhecidas metáforas raciais da sociedade contemporânea:

A assertiva de Justice Harlan de que "nossa Constituição é cega quanto à cor" é o mantra da atual política racial e do seu discurso, influenciando fortemente a jurisprudência constitucional moderna, assim como a forma pela qual pensamos e falamos sobre raça (HARRIS, 2004, p. 189, tradução nossa). ${ }^{30}$

A mesma crítica ao uso do argumento "antirracial" pela atual composição da Corte Suprema dos EUA é feita por Kendall Thomas, destacando que recentes Ministros têm arguido que a color-blindness do texto constitucional é necessária para evitar o despertar de discriminações passadas.

A marca textual do princípio da cegueira de cores na jurisprudência da Suprema Corte norte-americana é a famosa expressão da opinião dissidente do ministro

29 No original: "However, unlike Dred Scott, Plessy appears to have one saving virtue: Justice Harlan's solitary dissent denounced the majority's endorsement of de jure segregation as a 'thin disguise' through which the suppression of Blacks was legitimated and maintained. On one view, the genius of Harlan's dissent was its prescience: Even at a time when Black subordination was viewed as part of the natural order, Harlan condemned state-compelled segregation as a system of racial caste that was inconsistent with the constitutional grant of national citizenship under the Reconstruction Amendments" (HARRIS, 2004, p. 188).

No original: "Justice Harlan's assertion that '[o]ur constitution is color-blind' is the mantra of current racial politics and discourse, heavily influencing modern day constitutional jurisprudence as well as how we think and talk about race”(HARRIS, 2004, p. 189). 
Harlan em Plessy v. Ferguson: "A nossa Constituição é cega quanto à cor e nem distingue ou tampouco tolera classes entre os cidadãos”. Na composição atual da Corte, este compromisso de cegueira de cores tem encontrado seus defensores mais apaixonados nos ministros Antonin Scalia e Clarence Thomas. Em uma série de pronunciamentos cada vez mais estridentes sobre o significado da Cláusula de Proteção Igualitária, o ministro Scalia denunciou o uso da raça como critério na tomada de decisão sobre políticas públicas, mesmo para fins supostamente benignos. Scalia proibiria até mesmo as políticas que são destinadas a "compensar" discriminações passadas (THOMAS, 2002, p. 80, tradução nossa, grifos nossos). ${ }^{31}$

Em decisões recentes, Thomas destaca que a Corte busca evitar quaisquer usos do critério de raça - ainda que para ações benignas -, insinuando que toda decisão que leve em conta questões raciais (race-conscious) é discriminação, pura e simples (THOMAS, 2002, p. 80).

Estes são alguns dos desdobramentos do caso Plessy v. Ferguson que mantém vivas as polêmicas em torno da igualdade racial e demonstram o difícil caminho para uma convivência pacífica e integrada entre negros e brancos na história norte-americana.

Quanto às decisões da Suprema Corte dos EUA, finalmente em 1954 houve uma decisão que alterou radicalmente sua consolidada jurisprudência nas questões raciais e que merece uma detalhada análise do ambiente político ${ }^{32}$ no qual foi possível que a Corte assim decidisse.

\section{Nos MOINHOS DA Guerra Fria:}

POLÍTICA EXTERNA DAS QUESTÕES RACIAIS NO SÉCULO XX

\section{2. i A fraternidade para linda Brown, 1954:}

A SEGREGaÇão ESCOLAR COMO SENTIMENTO DE INFERIORIDADE

Em maio de 1954, praticamente dez anos antes das alterações legislativas que levaram aos Civil Rights Acts da década de 1960, o Chief Justice Earl Warren proferia a opinion of the Court

31 No original: "The textual lodestar of the color-blindness principle in U. S. Supreme Court case law is the famous language from Justice Harlan's dissenting opinion in Plessy v. Ferguson': "Our Constitution is color blind, and neither knows nor tolerates classes among citizens." On the current Court, this commitment to color-blindness has found its most passionate proponents in Justices Antonin Scalia and Clarence Thomas. In a series of increasingly strident pronouncements on the meaning of the Equal Protection Clause, Justice Scalia has denounced the use of race as a criterion in public decision making, even for putatively benign purposes. Scalia would forbid even those policies that are designed to 'make up' for past discrimination”" (THOMAS, 2002, p. 80, grifos nossos).

Apesar de Scott v. Sandford (1856) e Plessy v. Ferguson (1896) serem fundamentais para se compreender a igualdade racial nos EUA, são casos distintos de Brown v. Board of Education of Topeka (1954) no tocante 
no caso Brown v. Board of Education of Topeka, Kansas (U. S. SUPREME COURT, 1954), que declarava inconstitucionais todas as leis de segregação escolar nos Estados Unidos.

A ação coletiva foi organizada em 1950 por uma associação de direitos civis (National Association for the Advancement of Colored People - NAACP), que solicitou a um grupo de pais afro-americanos de diferentes Estados que tentassem matricular seus filhos em escolas só para brancos, com o objetivo de levar a Suprema Corte a revisar a tese da divisão racial estabelecida em Plessy v. Ferguson (a doutrina do separate but equal).

Oliver Brown tinha uma filha pequena, Linda, que foi inscrita na escola para brancos de Topeka. Brown era um dos 13 pais no polo ativo da demanda coletiva, mas que, por critérios de ordem alfabética, ficou em primeiro e passou a ser conhecido desta forma. O advogado principal pleiteando pelos reclamantes viria a ser o futuro membro da Suprema Corte, Justice Thurgood Marshall.

Em 1954, o objetivo da NAACP foi alcançado quando a Suprema Corte decidiu, por unanimidade, pela procedência da ação em Brown v. Board of Education of Topeka, afastando a doutrina do separate but equal e concluindo que a segregação de alunos negros e brancos em escolas distintas retirava das crianças afro-americanas a possibilidade de uma escolaridade enriquecedora e justa.

O primeiro desafio argumentativo do voto do Justice Warren foi contornar o extenso histórico de casos que confirmavam a segregação racial nas escolas com fundamento na omissão, por parte da $14^{\mathrm{a}}$ emenda, de quaisquer elementos relacionados a não discriminação na educação e de como a segregação racial era prática corrente no tempo dos legisladores de 1868, como explica Turner:

A Corte Brown considerou quatro casos oriundos dos Estados do Kansas, Carolina do Sul, Virgínia e Delaware em que os tribunais inferiores haviam rejeitado recursos fundamentados na $14^{a}$ Emenda sobre a segregação racial sancionada pelos Estados para estudantes de escolas públicas primárias e secundárias. Inicialmente arguidos em 1952, os casos retornaram à pauta para reargumentação “em grande parte dedicada às circunstâncias que rodearam a adoção da Décima Quarta Emenda em 1868” e às “considerações sobre a Emenda no Congresso, sua ratificação pelos Estados e as práticas então existentes de segregação racial, bem como os pontos de vista de defensores e opositores da Emenda” (TURNER, 2015, p. 55, tradução nossa). ${ }^{33}$

ao argumento desenvolvido sobre a influência das relações internacionais. Não obstante, merecem análise para a compreensão dos precedentes que moldaram os argumentos no caso Brown.

No original: "The Brown Court considered four cases from Kansas, South Carolina, Virginia, and Delaware in which the lower courts rejected Fourteenth Amendment challenges to state-sanctioned racial segregation of elemen- 
Para desvincular o caso Brown dos precedentes, Justice Warren indicou que aqueles não podiam ser utilizados como bases sólidas para resolver o problema atual da segregação escolar, uma vez que a educação de negros era, naquele tempo, praticamente inexistente:

A decisão do Ministro Presidente [Chief Justice] Warren afirmou que as fontes analisadas na reargumentação "lançaram alguma luz", mas "não foram suficientes para resolver o problema com que nos deparamos. Na melhor das hipóteses, elas são inconclusivas". Adotando uma espécie de jurisprudência sociológica, o Ministro Presidente explicou que, no momento da adoção da $14^{a}$ Emenda “[... ] a educação de negros era quase inexistente, e praticamente todos da raça eram iletrados. Na verdade, qualquer forma de educação de negros era proibida por lei em alguns Estados". [...] Levando em conta tais fatos e circunstâncias, o Ministro não ficou surpreso de que, na história da $14^{\mathrm{a}}$ Emenda, tão pouco havia sido debatido sobre seus efeitos pretendidos sobre a educação pública (TURNER, 2015, p. 55-56, tradução nossa). ${ }^{34}$

Em contraposição à sistemática exclusão dos negros do sistema escolar do século XIX, Warren declara um verdadeiro manifesto sobre o papel da educação como formativo de cidadãos ciosos de suas responsabilidades como bons cidadãos. A educação, afirmou Warren, seria a mais importante função do estado e determinante para o sucesso na futura carreira das crianças. A educação constituiria direito a ser disponibilizado a todos de forma igualitária:

\section{Hoje, a educação é talvez a função mais importante dos governos estaduais e locais. As leis sobre a frequência escolar obrigatória e os grandes investimentos em educação demonstram o reconhecimento da importância da educação para a nossa sociedade democrática. A educação é necessária no desempenho de nossas}

tary and secondary public school students. Initially argued during the Court's 1952 Term, the cases were set for reargument 'largely devoted to the circumstances surrounding the adoption of the Fourteenth Amendment in 1868' and the 'consideration of the Amendment in Congress, ratification by the states, then existing practices in racial segregation, and the views of proponents and opponents of the Amendment'” (TURNER, 2015, p. 55).

No original: “Chief Justice Warren's decision determined that the sources examined in the reargument 'cast some light' but were 'not enough to resolve the problem with which we are faced. At best, they are inconclusive.' Committing an act of sociological jurisprudence, Chief Justice Warren explained that at the time of the adoption of the Fourteenth Amendment [...] the '[e]ducation of Negroes was almost nonexistent, and practically all of the race were illiterate. In fact, any education of Negroes was forbidden by law in some states.' [...] Given these facts and circumstances, the Chief Justice was not surprised that there should be so little in the history of the Fourteenth Amendment relating to its intended effect on public education" (TURNER, 2015, p. 55-56). 
responsabilidades públicas mais básicas, até mesmo para o serviço nas forças armadas. É a própria base da boa cidadania. Hoje é um instrumento fundamental para o despertar de valores culturais na criança, preparando-a para a formação profissional posterior, bem como para ajudá-la a se ajustar normalmente ao meio ambiente. Nestes dias, é duvidoso que qualquer criança possa razoavelmente esperar ter sucesso na vida se a ela lhe for negada a oportunidade da educação. Tal oportunidade, onde o Estado se comprometeu a fornecê-la, é um direito que deve ser disponibilizado a todos em igualdade de condições (U. S. SUPREME COURT, 1954, p. 3-4, tradução nossa, grifos nossos). ${ }^{35}$

$\mathrm{O}$ argumento principal para a decisão da Corte fundamentou-se em estudos científicos que demonstravam os impactos psicológicos da segregação escolar, indicando que as crianças negras poderiam ter sentimentos de inferioridade que as afetariam intensamente, como indica Kendall Thomas:

A principal preocupação constitucional da Corte era como a segregação racial escolar obrigatória fazia as crianças negras se sentirem. As escolas públicas segregadas por raça geravam um "sentimento de inferioridade" entre os estudantes negros, induzindo um status na comunidade que poderia afetar seus corações e mentes de uma maneira improvável de ser desfeita (THOMAS, 2002, p. 229, tradução nossa). ${ }^{36}$

Desta forma, Warren conclui que:

Separar crianças negras de outras de idade e qualificação similares somente por causa de sua raça gera um senso de inferioridade assim como de seu status na comunidade,

No original: "Today, education is perhaps the most important function of state and local governments. Compulsory school attendance laws and the great expenditures for education both demonstrate our recognition of the importance of education to our democratic society. It is required in the performance of our most basic public responsibilities, even service in the armed forces. It is the very foundation of good citizenship. Today it is a principal instrument in awakening the child to cultural values, in preparing him for later professional training, and in helping him to adjust normally to his environment. In these days, it is doubtful that any child may reasonably be expected to succeed in life if he is denied the opportunity of an education. Such an opportunity, where the state has undertaken to provide it, is a right which must be made available to all on equal terms” (U. S. SUPREME COURT, 1954, p. 3-4, grifos nossos). feel. Racially segregated public schools generated a 'feeling of inferiority' among Black students about status in the community that may affect their hearts and minds in a way unlikely ever to be undone" (THOMAS, 2002, p. 229). 
de tal forma que pode afetar seus corações e mentes de forma dificilmente reversível (U. S. SUPREME COURT, 1954, p. 4, tradução nossa). ${ }^{37}$

Como consequência, o precedente do caso Plessy v. Ferguson estava declaradamente superado, assim como a doutrina do separate but equal.

Uma leitura rápida do caso poderia fazer crer que, decorridos praticamente 60 anos desde Plessy, a sociedade norte-americana havia certamente amadurecido nas relações interraciais e composto uma rica paleta de amplos matizes no espectro racial.

Entretanto, as reações à decisão da Suprema Corte no caso Brown demonstram o oposto. Grande parte dos Estados do Sul dos EUA buscou formas de invalidar a decisão por meio de legislação Estadual que impossibilitasse ou ao menos dificultasse que alunos negros frequentassem as escolas para brancos.

Empregando a doutrina da intervenção e negação, a maioria dos Estados da antiga Confederação aprovou resoluções declarando a decisão em Brown nula e sem efeito. Por exemplo, em fevereiro de 1956, o Estado da Virginia resolveu usar "todos os honrosos meios legais e constitucionais" para "resistir a esta ilegal intervenção nos nossos poderes soberanos". A “doutrina Parker" postulava que a Constituição “não requer integração. Tão somente proíbe a discriminação” (TURNER, 2015, p. 60, tradução nossa). ${ }^{38}$

Em certas escolas, houve a necessidade de intervenção militar para garantir o cumprimento da decisão, como na Little Rock Central High School, no Estado do Arkansas, e na escola primária William Frantz, em Nova Orleans, Louisiana, conforme o relato de Ronald Turner:

Em 1957, uma multidão inicialmente frustrou a inscrição de nove estudantes afroamericanos na Little Rock Central High School. O Presidente Dwight D. Eisenhower enviou para Little Rock mil soldados da $101^{\text {a }}$ Divisão Aerotransportada para restaurar a ordem e os alunos conseguiram se inscrever. Três anos mais tarde, agentes federais escoltaram o menino Ruby Bridges, de seis anos de idade, para permitir seu ingresso na William Frantz

37 No original: "To separate them from others of similar age and qualifications solely because of their race generates a feeling of inferiority as to their status in the community that may affect their hearts and minds in a way unlikely ever to be undone”(U. S. SUPREME COURT, 1954, p. 4).

38 No original: "A majority of the states of the former Confederacy, employing the doctrine of interposition and nullification, passed resolutions declaring Brown null and void. For instance, in February 1956 Virginia resolved to use 'all honorable, legal and constitutional' means to 'resist this illegal encroachment on our sovereign powers.' The 'Parker Doctrine' posited that the Constitution 'does not require integration. It merely forbids discrimination"” (TURNER, 2015, p. 60). 
Elementary School, em Nova Orleans, Louisiana [...]. A criança foi “o primeiro aluno negro a integrar uma escola”, em Nova Orleans (TURNER, 2015, p. 60-61, tradução nossa). ${ }^{39}$

Assim, como explicar a audácia da Corte em proferir tal decisão controvertida? Alguns elementos nos permitem especular que, se os Ministros da Corte Warren puderam ter a coragem de agir com certo ativismo ao subverter os tradicionais - e racistas - precedentes da Corte, o fizeram não somente por mérito próprio, mas talvez também por uma feliz convergência de interesses políticos que os incentivaram a tanto.

É o que se argumenta a seguir.

\subsection{INDÍCIOS DE MOTIVAÇÃO POLÍTICA:}

A DISCRIMINAÇÃO RACIAL COMO UMA FONTE DE CONSTANTE EMBARAÇOS PARA O GOVERNO Como visto, o fim da segregação racial nas escolas decidido em Brown antecipava em praticamente 10 anos a maioria legislativa que aprovaria o Civil Rights Act de 1964.

Ao contrário do que se poderia supor, a decisão unânime da Suprema Corte no caso Brown atendia interesses do Governo. É o que indica Aryeh Neier, em sua nota comemorativa sobre os 50 anos do caso Brown v. Board of Education, em 2014:

A decisão no caso Brown serviu aos interesses dos Estados Unidos durante a Guerra Fria, quando a nação estava competindo com a União Soviética pela influência global. O governoTruman reconheceu isso expressamente no início de 1950, quando peticionou como amicus curiae na Suprema Corte em dezembro de 1952, solicitando o resultado que o tribunal anunciou 17 meses mais tarde. A petição da administração Truman era bastante incomum por causa de sua forte ênfase em considerações de política externa em um caso ostensivamente sobre questões domésticas. Das sete páginas cobrindo "o interesse dos Estados Unidos", cinco são focadas na forma pela qual a segregação escolar atinge negativamente os Estados Unidos na Guerra Fria, em sua competição [com a União Soviética] pela amizade e lealdade dos povos não brancos em países que recentemente haviam conquistado sua independência do domínio colonial (NEIER, 2014, p. 2 , tradução nossa, grifo nosso) ${ }^{40}$

No original: "In 1957 a mob initially thwarted the enrollment of nine African American students at the Little Rock Central High School. President Dwight D. Eisenhower dispatched to Little Rock one thousand soldiers from the 101st Airborne Division to restore order and the students were able to enroll. Three years later federal marshals escorted six-year-old Ruby Bridges into the William Frantz Elementary School in New Orleans, Louisiana [...].The child was 'the first black pupil to integrate a school' in New Orleans" (TURNER, 2015, p. 60-61). nation was vying with the Soviet Union for global influence. The Truman administration recognized this in the early 
Da mesma forma, Mary L. Dudziak coloca a decisão da Suprema Corte como um caso diretamente relacionado à Guerra Fria entre os Estados Unidos e a União Soviética na luta pela hegemonia no mundo, como sugere em seu artigo Brown as a Cold War case, de 2004.

A União Soviética aproveitou essa fraqueza norte-americana. O racismo americano foi um dos principais temas da propaganda soviética no final dos anos 1940. Embora a propaganda fosse exagerada, no entanto alcançou um impacto porque a longa história de opressão dos afro-americanos era bem conhecida em todo o mundo. Muitos acreditavam que a liderança global norte-americana e a própria paz mundial dependeriam primeiramente de como a nação resolveria seus problemas raciais. Como Gunnar Myrdal afirmou em 1944, "Os Estados Unidos, por seu prestígio internacional, poder e segurança no futuro, precisam demonstrar ao mundo que americanos negros podem ser satisfatoriamente integrados em sua democracia” (DUDZIAK, 2004, p. 2, tradução nossa, grifo nosso) ${ }^{41}$

Outras indicações do impacto que as propagandas soviéticas tinham no imaginário político norte-americano podem ser notadas na forma pela qual a decisão do caso Brown foi divulgada. Como relatam Philip Klinkner e Rogers Smith em seu livro The unsteady march: the rise and decline of racial equality in America, as manifestações públicas associaram a decisão da Suprema Corte a uma vitória contra o comunismo e uma garantia à causa do mundo livre, entre outras afirmações ufanistas:

Menos de uma hora depois que o voto havia sido proferido, a Voz da América estava transmitindo a notícia ao redor do mundo em trinta e quatro idiomas [...]. Mais tarde, o deputado Adam Clayton Powell chamou o momento de "brilhante hora da democracia" e a "maior derrota que o comunismo já sofreu”.

1950s, when it filed a friend of the court brief with the Supreme Court in December 1952, calling for the result that the court announced 17 months later. The Truman administration's brief was highly unusual because of its heavy emphasis on foreign-policy considerations in a case ostensibly about domestic issues. Of the seven pages covering "the interest of the United States," five focused on the way school segregation hurt the United States in the Cold War competition for the friendship and allegiance of non-white peoples in countries then gaining independence from colonial rule" (NEIER, 2014, p. 2, grifo nosso).

41 No original: "The Soviet Union took advantage of this American weakness. American racism was a principal Soviet propaganda theme by the late 1940s. This propaganda was overblown, yet it had an impact because the long history of oppression of African Americans was well known around the world. Many believed that American world leadership, and world peace itself, hinged on the nation solving its racial problems. As Gunnar Myrdal put it in 1944, 'America, for its international prestige, power, and future security, needs to demonstrate to the world that American Negroes can be satisfactorily integrated into its democracy'” (DUDZIAK, 2004, p. 2, grifo nosso). 
Em um comunicado de imprensa, o Comitê Nacional Republicano afirmou que a decisão "pertence de forma adequada ao ataque de muitas frentes que o governo Eisenhower lança sobre o comunismo global. A igualdade humana em casa é uma arma da liberdade [...]. A decisão ajuda a garantir a causa do mundo livre" (KLINKNER; SMITH, 1999 , p. 239, tradução nossa, grifo nosso). ${ }^{42}$

Ainda mais evidente que os discursos do contexto de propaganda de guerra, um jornal de Atlanta estampava que a decisão era um "passo gigante para a democracia em casa e no mundo" e como uma "efetiva e sonora resposta às críticas comunistas do tratamento que damos ao nosso grupo minoritário" (KLINKNER; SMITH, 1999, p. 240, tradução nossa). ${ }^{43}$

Finalmente, a política externa também foi o mote da própria associação (NAACP) para angariar fundos para ajuizar a ação no caso Brown:

Em 1952, a NAACP patrocinou o caso Brown v. Board of Education of Topeka na Suprema Corte, alegando que a segregação na educação pública era inerentemente desigual. Ao arrecadar fundos para o litígio, a NAACP buscou colocar o caso no contexto da Guerra Fria, pedindo para "CONTRIBUIÇÕES DE CIDADÃOS QUE ENTENDEM SEU SIGNIFICADO PARA A VIDA NACIONAL E SEU IMPACTO NA LUTA MUNDIAL”. Em sua petição para a Suprema Corte, os advogados da NAACP arguiram que "A América do século XX, em sua luta contra o racismo no país e no estrangeiro, rejeitou a visão sobre raça constante em Plessy v. Ferguson, porque chegou à conclusão de que tais pontos de vista, obviamente, não tendem a preservar a força, mas tão somente a fraqueza do nosso património". Eles alegaram que a "sobrevivência do nosso país na atual situação internacional está inevitavelmente ligada à resolução desta questão doméstica" (KLINKNER; SMITH, 1999, p. 234, tradução nossa). ${ }^{44}$

No original: "Less than an hour after the opinion was handed down, the Voice of America was broadcasting the news around the world in thirty-four languages. [...] Later, Congressman Adam Clayton Powell called it the 'shining hour of democracy' and the 'greatest defeat that communism has received.' In a press release, the Republican National Committee claimed that the decision 'falls appropriately within the Eisenhower Administration's many-frontal attack on global Communism. Human equality at home is a weapon of freedom [...] It helps guarantee the Free World's cause" (KLINKNER; SMITH, 1999, p. 239, grifo nosso).

No original: "Although most Southerners were sharply critical of the Court's rulling, some conceded foreign policy advantages. According to one Atlanta newspaper, "local leaders and educators" viewed the decision "as a giant step forward for democracy at home and abroad." A member of the city's board of education praised the decision as "an effective and resounding reply to the Communist criticism of our treatment of our minority group" (KLINKNER; SMITH, 1999, p. 240).

44 No original: "In 1952, the NAACP brought the case of Brown v. Board of Education of Topeka before the Supreme Court, arguing that segregation in public education was inherently unequal. In appealing for funds to mount their challenge, the 
Mas a peça mais importante para demonstrar a influência de interesses do governo na decisão da Corte Suprema estava na manifestação (brief) por parte do Governo dos Estados Unidos, destacando que a desagregação das escolas públicas era de importância crítica para a política externa nacional.

Tal manifestação era subscrita pelo procurador-geral (Attorney General) dos Estados Unidos, James P. McGranery, em dezembro de 1952, na condição de amicus curiae.

Eis alguns trechos selecionados da petição, iniciando pelo argumento de que a capital dos EUA, Washington, servia como vitrine para o mundo das práticas racistas da sociedade americana:

Petição do Governo dos EUA como amicus curiae no caso Brown v. Board of Education.

O interesse dos Estados Unidos.

Nos últimos anos, o Governo Federal tem cada vez mais reconhecido a sua

responsabilidade especial para garantir a defesa dos direitos civis fundamentais

garantidos pela Constituição. [...]

O problema da discriminação racial é particularmente agudo no Distrito de Columbia, a capital do país. Esta cidade é a janela através da qual o mundo olha para a nossa casa. As embaixadas, legações e representantes de todas as nações estão aqui, na sede do Governo Federal. Funcionários estrangeiros e visitantes naturalmente julgam este país e o nosso povo por suas experiências e observações na capital da nação; e o tratamento de pessoas de cor aqui é tomado como a medida da nossa atitude para com as minorias em geral. O Presidente afirmou que "O Distrito de Columbia deve ser um verdadeiro símbolo da liberdade americana e democracia para o nosso povo, e para as pessoas do mundo”. Em vez disso, como o Comitê da presidência sobre os Direitos Civis relatou, o Distrito de Columbia "é uma ilustração gráfica de uma falha da democracia” (McGRANERY, 1952, p. 1, tradução nossa, grifo nosso). ${ }^{45}$

NAACP sought to place the case in the context of the ColdWar by asking for 'CONTRIBUTIONS FROM CITIZENSWHO UNDERSTAND SIGNIFICANCE TO NATIONAL LIFE AND IMPACT UPON WORLD STRUGGLE. In its brief to the Supreme Court, the NAACP's lawyers argued, 'Twentieth century America, fighting racism at home and abroad, has rejected the race views of Plessy v. Ferguson because we have come to the realization that such views obviously tend to preserve not the strength but the weakness of our heritage.'They claimed that the 'survival of our country in in the present international situation is inevitably tied to resolution of this domestic issue"” (KLINKNER; SMITH, 1999, p. 234).

45 No original: “US Gov't Amicus Curiae brief for Brown v. Bd. of Education. The interest of the United States. In recent years the Federal Government has increasingly recognized its special responsibility for assuring vindication of the fundamental civil rights guaranteed by the Constitution. [...] The problem of racial discrimination is particularly acute in the District of Columbia, the nation's capital. This city is the window through which the 
McGranery relata ainda que os estrangeiros negros que circulavam por Washington, alguns membros de missões diplomática, eram por vezes confundidos por negros americanos e proibidos de entrar e frequentar determinados lugares públicos. Tais problemas de discriminação racial deveriam, para McGranery, ser vistos no contexto da batalha mundial entre liberdade e tirania:

A vergonha e o absurdo no tratamento de negros norte-americanos de Washington são realçados pela presença de muitos visitantes estrangeiros de pele escura. Os costumes da capital não só humilham cidadãos de cor, mas são também fonte de embaraços consideráveis para esses visitantes [...]. Funcionários estrangeiros são muitas vezes confundidos com os negros americanos e têm recusados alimentação, alojamento e entretenimento. No entanto, uma vez esclarecido de que eles não são os americanos, recebem a acomodação devida. É no contexto da presente luta mundial entre liberdade e tirania que o problema da discriminação racial deve ser visto (McGRANERY, 1952, p. 1, tradução nossa, grifo nosso). ${ }^{46}$

A petição passa a ser mais explícita, afirmando com todas as letras que:

Os Estados Unidos estão tentando provar ao povo do mundo, de todas as nacionalidades, raça e cor, que a democracia livre é a mais segura e civilizada forma de governo já criada pelo homem. Temos que estabelecer o exemplo para os outros, mostrando firme determinação de remover as falhas existentes em nossa democracia (McGRANERY, 1952, p. 2 , tradução nossa). ${ }^{47}$

world looks into our house. The embassies, legations, and representatives of all nations are here, at the seat of the Federal Government. Foreign officials and visitors naturally judge this country and our people by their experiences and observations in the nation's capital; and the treatment of colored persons here is taken as the measure of our attitude toward minorities generally. The President has stated that 'The District of Columbia should be a true symbol of American freedom and democracy for our own people, and for the people of the world.' Instead, as the President's Committee on Civil Rights found, the District of Columbia 'is a graphic illustration of a failure of democracy'” (McGRANERY, 1952, p. 1, grifo nosso).

No original: “The shamefulness and absurdity of Washington's treatment of Negro Americans is highlighted by the presence of many dark-skinned foreign visitors. Capital custom not only humiliates colored citizens, but is a source of considerable embarrassment to these visitors. *** Foreign officials are often mistaken for American Negroes and refused food, lodging and entertainment. However, once it is established that they are not Americans, they are accommodated. It is in the context of the present world struggle between freedom and tyranny that the problem of racial discrimination must be viewed” (McGRANERY, 1952, p. 1, grifo nosso).

47 No original: "The United States is trying to prove to the people of the world, of every nationality, race, and color, that a free democracy is the most civilized and most secure form of government yet devised by man. We must set an 
O comunismo é então introduzido como problema, demonstrando que a existência de discriminação contra minorias nos Estados Unidos teria um efeito adverso nas relações com outros países, dando impulso à propaganda comunista e lançando dúvidas sobre a intensidade da devoção norte-americana à fé democrática:

A existência de discriminação contra grupos minoritários nos Estados Unidos tem um efeito adverso sobre as nossas relações com outros países. A discriminação racial fornece combustível para as usinas de propaganda comunista e levanta dúvidas, até mesmo entre nações amigas, quanto à intensidade da nossa dedicação à fé democrática (McGRANERY, 1952 , p. 2 , tradução nossa). ${ }^{48}$

Para fortalecer seu argumento, o procurador-geral transcreveu trechos de uma carta que solicitara ao Secretário de Estado, Dean Acheson, sobre a importância do julgamento do caso Brown para a política externa norte-americana:

Em resposta ao pedido do Procurador-Geral para uma declaração oficial sobre os efeitos da discriminação racial nos Estados Unidos na condução das relações exteriores, o Secretário de Estado [Ministro das Relações Exteriores] escreveu o seguinte: “[...] Escrevi ao presidente do Comitê de Práticas para o Emprego Justo, em 8 de maio de 1946, que a existência de discriminação contra grupos minoritários estava tendo um efeito adverso sobre as nossas relações com outros países. Naquela época, eu salientei que a discriminação contra esses grupos nos Estados Unidos criara desconfiança e ressentimento em outros países e que teríamos melhores relações internacionais caso estes motivos para desconfiança e ressentimento fossem removidos" (ACHESON apud McGRANERY, 1952, p. 2, tradução nossa). ${ }^{49}$

example for others by showing firm determination to remove existing flaws in our democracy" (McGRANERY, 1952, p. 2).

48 No original: "The existence of discrimination against minority groups in the United States has an adverse effect upon our relations with other countries. Racial discrimination furnishes grist for the Communist propaganda mills, and it raises doubts even among friendly nations as to the intensity of our devotion to the democratic faith" (McGRANERY, 1952, p. 2).

49 No original: "In response to the request of the Attorney General for an authoritative statement of the effects of racial discrimination in the United States upon the conduct of foreign relations, the Secretary of State has written as follows: '[...] I wrote the Chairman of the Fair Employment Practices Committee on May 8, 1946, that the existence of discrimination against minority groups was having an adverse effect upon our relations with other countries. At that time I pointed out that discrimination against such groups in the United States created suspicion and resentment in other countries, and that we would have better international relations were these reasons for suspicion and resentment to be removed'” (ACHESON apud McGRANERY, 1952, p. 2). 
Em sua continuação, Dean Acheson afirma que desde 1946 a segregação racial trazia danos às relações exteriores do país, pois haviam constantes críticas às práticas de discriminação contra minorias, nos EUA, pela imprensa estrangeira, pela rádio e nas Nações Unidas. Ao final, destaca a acusação corrente de que os EUA seriam hipócritas ao reivindicar serem campeões de democracia enquanto permitem práticas de discriminação racial em seu país:

Durante os últimos seis anos, os danos às nossas relações exteriores atribuíveis a essa fonte tornaram-se progressivamente maiores. Na imprensa estrangeira, através de rádios estrangeiras e em organismos internacionais tais como as Nações Unidas, os Estados Unidos estão sob o ataque constante por causa de várias práticas de discriminação contra grupos minoritários no país. Como seria de esperar, os porta-vozes soviéticos exploram regularmente esta situação na propaganda contra os Estados Unidos, tanto no âmbito das Nações Unidas quanto por meio da rádio e da imprensa, que chega a todos os cantos do mundo. Alguns desses ataques contra nós são baseados em mentiras ou distorções; mas a inegável existência de discriminação racial dá aos governos hostis o tipo mais eficaz de munição para sua guerra de propaganda. A reação hostil entre povos normalmente amigáveis, muitos dos quais são particularmente sensíveis no que diz respeito à condição de raças não europeias, está crescendo em proporções alarmantes. Nesses países, é crescente a opinião externada abertamente de que os Estados Unidos são hipócritas no que diz ser os campeões da democracia, permitindo simultaneamente práticas de discriminação racial em seu território (ACHESON apud McGRANERY, 1952, p. 3, tradução nossa). ${ }^{\mathbf{5 0}}$

Acheson reconhece que, embora houvesse progressos sendo feitos, "a continuidade da discriminação racial nos EUA se mantém como fonte de embaraço constante e diário para

50 No original: "During the past six years, the damage to our foreign relations attributable to this source has become progressively greater. The United States is under constant attack in the foreign press, over the foreign radio, and in such international bodies as the United Nations because of various practices of discrimination against minority groups in this country. As might be expected, Soviet spokesmen regularly exploit this situation in propaganda against the United States, both within the United Nations and through radio broadcasts and the press, which reaches all corners of the world. Some of these attacks against us are based on falsehood or distortion; but the undeniable existence of racial discrimination gives unfriendly governments the most effective kind of ammunition for their propaganda warfare. The hostile reaction among normally friendly peoples, many of whom are particularly sensitive in regard to the status of non-European races, is growing in alarming proportions. In such countries the view is expressed more and more vocally that the United States is hypocritical in claiming to be the champion of democracy while permitting practices of racial discrimination here in this country" (ACHESON apud McGRANERY, 1952 , p. 3). 
este governo nas relações exteriores, sabotando a efetiva manutenção de nossa liderança moral das nações livres e democráticas do mundo" (ACHESON apud McGRANERY, 1952, p. 3). ${ }^{51}$

Finalizando sua petição como amicus curiae, McGranery faz o apelo final para que a Corte auxilie o governo a ser exemplo de liberdade e verdadeira democracia para inspirar os homens bons em todo o mundo. Eis o texto carregado de retórica ufanista:

Conclusão: A posição subordinada ocupada por negros neste país como resultado de discriminação governamentais ("cidadania de segunda classe", como às vezes é chamada) apresenta um problema não resolvido para a democracia norte-americana, um desafio incontornável para a sinceridade da nossa adesão à fé

democrática. Nestes dias em que o mundo livre deve conservar e fortalecer as fontes morais e materiais de sua força, é especialmente importante afirmar que a Constituição dos Estados Unidos não impõe limitação, expressa ou implícita, ao princípio da igualdade de todos os homens perante a lei. É o que o ministro Harlan disse em seu voto vencido no caso Plessy (163 U. S. em 562):

Nós nos orgulhamos da liberdade de que goza o nosso povo acima de todos os outros povos. Mas é difícil conciliar tal soberba com a situação jurídica que, na prática, coloca a marca de servidão e degradação sobre uma grande classe de nossos concidadãos, nossos iguais perante a lei.

O Governo e o povo dos Estados Unidos devem provar através de suas ações que os ideais expressos na Declaração de Direitos são realidades vivas, não abstrações literárias. Como o Presidente declarou:

Se queremos inspirar os povos do mundo cuja liberdade está em perigo, se queremos restaurar a esperança para aqueles que já perderam as suas liberdades civis, se quisermos cumprir nossa promessa, devemos corrigir as imperfeições remanescentes na nossa prática da democracia.

Nós sabemos o caminho. Precisamos apenas da vontade.

Respeitosamente.

(McGRANERY, 1952, p. 3, tradução nossa, grifos nossos). ${ }^{\mathbf{5 2}}$

51 No original: "Although progress is being made, the continuance of racial discrimination in the United States remains a source of constant embarrassment to this Government in the day-to-day conduct of its foreign relations; and it jeopardizes the effective maintenance of our moral leadership of the free and democratic nations of the world" (ACHESON apud McGRANERY, 1952, p. 3).

No original: "Conclusion: The subordinate position occupied by Negroes in this country as a result of governmental discriminations ("second-class citizenship," as it is sometimes called) presents an unsolved problem for American democracy, an inescapable challenge to the sincerity of our espousal of the democratic 
Tal petição consta dos autos do processo, mas apesar disso seus argumentos não foram citados direta ou indiretamente no voto redigido por Justice Harlan. Seria isso indício de que a Suprema Corte não queria ser vista como atendendo a uma solicitação do governo? Infelizmente, não temos dados para ir além da mera especulação.

Com relação à aproximação entre política interna, movimentos de direitos dos negros e da Guerra Fria, há muitos elementos a demonstrar que houve uma convergência de interesses (na teoria proposta por Derrick Bell [1980]) a potencializar o movimento do pêndulo da história.

O momento histórico do início da Guerra Fria criou um cenário único de interesses congruentes que possibilitaram à Suprema Corte uma decisão desafiadora, que ultrapassa a segregação racial profundamente enraizada em práticas do cotidiano norte-americano.

\section{CONSIDERAÇÕES FINAIS: VENTOS DA SUPREMA CORTE}

Nos três casos narrados neste artigo, a Suprema Corte norte-americana precisou equilibrar suas decisões nos interesses fragmentados entre os diferentes atores políticos e na sociedade.

Embora aparentemente contraditórios entre si, os três casos da Corte envolvendo questões de raça (casos Dred Scott v. Sandford, 1856; Plessy v. Ferguson, 1896 e Brown v. Board of Education of Topeka, 1954) não devem ser vistos como uma sequência linear ou argumentativa de jurisprudência. Ao contrário, seu valor está muito mais nas diferentes formas com que as diferentes composições da Corte lidaram com as pressões da sociedade e da comunidade política fragmentada, na tentativa de conciliar interesses dificilmente convergentes.

Enquanto em Dred Scott, de 1856, a saída foi procedimental (negando a Scott a legitimidade ativa por falta de cidadania), atendendo assim a manutenção do status quo político e inflamando os ânimos que flambaram definitivamente na guerra civil dez anos mais tarde, no caso Plessy, de 1896, o movimento foi inverso, permitindo que alguns Estados contornassem

faith. In these days, when the free world must conserve and fortify the moral as well as the material sources of its strength, it is especially important to affirm that the Constitution of the United States places no limitation, express or implied, on the principle of the equality of all men before the law. Mr. Justice Harlan said in his dissent in the Plessy case (163 U. S. at 562): We boast of the freedom enjoyed by our people above all other peoples. But it is difficult to reconcile that boast with a state of the law which, practically, puts the brand of servitude and degradation upon a large class of our fellowcitizens, our equals before the law. The Government and people of the United States must prove by their actions that the ideals expressed in the Bill of Rights are living realities, not literary abstractions. As the President has stated: If we wish to inspire the people of the world whose freedom is in jeopardy, if we wish to restore hope to those who have already lost their civil liberties, if we wish to fulfill the promise that is ours, we must correct the remaining imperfections in our practice of democracy. We know the way. We need only the will. Respectfully submitted" (McGRANERY, 1952, p. 3, grifos nossos). 
os efeitos das Emendas da Reconstrução (13, $14^{\mathrm{a}}$ e $15^{\mathrm{a}}$ emendas) e estabelecem legislações segregacionistas, com a chancela da Corte Suprema.

No terceiro caso, Brown v. Board of Education of Topeka, de 1954, a Corte quebrou sua tradição de conservadorismo nas questões raciais. Neste caso, a política externa foi um argumento recorrente das manifestações políticas anteriores (o próprio mote da NAACP para arrecadar fundos) e posteriores (discursos políticos e jornais) à decisão. O contexto da Guerra Fria e a guerra ideológica contra a União Soviética não foram citados na decisão da Corte, mas pairam como matizes de uma policromia convergente, uma feliz contingência que auxilia a Corte a agregar apoio político em torno de sua decisão.

Não podemos afirmar que a mudança de entendimento da Corte - que resultou na declaração de inconstitucionalidade das leis de segregação racial nas escolas - teve como único fundamento a política externa de um governo interessado em fazer uma bela imagem de si no cenário internacional. Entretanto, pode-se especular com certo lastro que o contexto da Guerra Fria aumentou a margem de liberdade da Corte, ou ao menos, diminuiu a oposição política e social a uma decisão que não teria sido tão bem aceita, caso a concorrência soviética não existisse.

Neste aspecto, enquanto a segregação racial dos anos 1950 servia como água para movimentar os moinhos da propaganda soviética antinorte-americana, tais moinhos podem ter fornecido os bons ventos que impulsionaram a Suprema Corte a uma corajosa decisão no caso Brown.

\section{REFERÊNCIAS}

BALKIN, Jack M.; LEVINSON, Sanford. 13 ways of looking at Dred Scott. Chicago-Kent Law Review, v. 82, 2007. Disponível em: <http://digitalcommons.law.yale.edu/fss_papers/229/>. Acesso em: 8 out. 2015.

BELL, Derrick A. Board of education and the interest-convergence dilemma. In: CRENSHAW, K.; GOTANDA, N.; PELLER, G.; THOMAS, K. (Eds.). Critical race theory: The key writings that formed the movement. New York: New Press, 1995. 
COVER, Robert M. The origins of judicial activism in the protection of minorities. The Yale Law Journal, v. 91, n. 7, 1982. Disponível em: <http://digitalcommons.law.yale.edu/fss_papers/2704>. Acesso em: 3 ago 2015.

DUDZIAK, Mary. Brown as a cold war case. The Journal of American History, v. 91, n. 1, p. 32-42, 2004. Disponível em: <http://www.history.ucsb.edu/courses/tempdownload.php?attach_id=5781>. Acesso em: 2 ago. 2015.

GRABER, Mark A. Dred Scott and the problem of constitutional evil. New York: Cambridge University Press, 2006.

HARRIS, Cheryl L. The story of Plessy v. Ferguson: The death and resurrection of racial formalism. In: DORFF, Michael. (Ed.). Constitutional Law Stories. New York: Foundation Press, 2004.

KLINKNER, Philip A.; SMITH, Rogers M. The unsteady march: The rise and decline of racial equality in America. Chicago: University of Chicago Press, 1999.

LESTER, Anthony. Brown v. Board of Education overseas. Proceedings of the American Philosophical Society held at Philadelphia for promoting useful knowledge, v. 148, n. 4, p. 455-463, 2004. Disponível em: <www.amphilsoc.org/sites/default/files/proceedings/480405.pdf>. Acesso em: 02 ago. 2015.

MALTZ, Earl M. The last angry man: Benjamin Robbins Curtis and the Dred Scott case. ChicagoKent Law Review, v. 82, p. 265-276, 2007. Disponível em: <http://scholarship.kentlaw.iit.edu/ cklawreview/vol82/iss1/9/>. Acesso em: 8 set. 2015.

McGRANERY, James P. Attorney General. US Gov't Amicus Curiae brief for Brown v. Bd. of Education. dez. 1952. Disponível em: <http://www-rohan.sdsu.edu/ jputman/410b/amicusbriefbrownvboard.htm>. Acesso em: 4 ago. 2015.

MILNER IV, H. Richard; LOMOTEY, Kofi. Handbook of urban education. London: Routledge, 2014.

NEIER, Aryeh. Brown v. Board of Education: key Cold War weapon. Reuters, London, 14 mai. 2014. Disponível em: <http: / /blogs.reuters.com/great-debate/2014/05/14/brown-v-board-of-ed-keycold-war-weapon/>. Acesso em: 3 ago 2015.

SUNSTEIN, Cass R. Did Brown matter? (Brown v. Board of Education). The New Yorker, v. 80, n. 10, p. 102, mai. 2004. Disponível em: <http://www.newyorker.com/magazine/2004/05/03/didbrown-matter $>$. Acesso em: 2 ago. 2015. 
THOMAS, Kendall. Racial justice: moral or political? In: SARAT, Austin; GARTH, Bryant; KAGAN, Robert A. (Eds.). Looking back at law's century. New York: Cornell University Press, 2002.

TURNER, Ronald. The way to stop discrimination on the basis of race... Stanford Journal of Civil Rights and Civil Liberties, v. 11, p. 45-88, abr. 2015. Disponível em: <http://ssrn.com/abstract=2592570>. Acesso em: 19 ago. 2015.

U. S. SUPREME COURT. Brown v. Board of Ed. of Topeka, Shawnee County, Kan., 347 U. S. 483, 1954.

U. S. SUPREME COURT. Dred Scott v. Sandford, 60 U. S. (19 How.) 393, 407, 1856.

U. S. SUPREME COURT. Plessy v. Ferguson, 163 U. S. 537, 549, 1896.

Sandro Luís Tomás Ballande Romanelli

Mestre em Direito Público pela Universidade Federal DO PARANÁ - UFPR. DOUTOR EM DiREITOS HUMANOS E Democracia PELA UFPR. Professor do INSTITUTO FEDERAL DO PARANÁ - IFPR. sromanelliagmail.com

Fabrício Ricardo de Limas Tomio Mestre em Sociologia Política pela Universidade Federal de Santa Catarina - UfSC. Doutor em CiÊncia Política Pela Unicamp. Professor dos Programas de Pós-Graduação em Direito e Ciência Política da Universidade Federal do PARANÁ - UFPR. fab_tomahotmail.com 